\title{
DESIGN OF ATOMIZERS AND BURNERS FOR COAL-WATER SLURRY COMBUSTION
}

\author{
QUARTERLY ACTIVITY REPORT \\ Period Starting: 1 July 1997 \\ Period Ending: 30 September 1997
}

Norman Chigier and William Humphrey

30 September 1997

DOE Award Number: DE-FG22-95PC95105 -- 8

Spray Systems Technology Center

Carnegie Mellon University

5000 Forbes Avenue

Pittsburgh, PA 15213 


\section{Disclaimer}

This report was prepared as an account of work sponsored by an agency of the United States Government. Neither the United States Government nor any agency thereof, nor any of their employees, makes any warranty, express or implied, or assumes any legal liability or responsibility for the accuracy, completeness, or usefulness of any information, apparatus, product, or process disclosed, or represents that its use would not infringe privately owned rights. Reference herein to any specific commercial product, process, or service by trade name, trademark, manufacturer, or otherwise does not necessarily constitute or imply its endorsement, recommendation, or favoring by the United States Government or any agency thereof. The views and opinions of authors expressed herein do not necessarily state or reflect those of the United States Government or any agency thereof. 


\section{Abstract}

In preparation for coal-water slurry tests, a Delavan nozzle was characterized using water and a Malvern 2600 particle sizer. Actual tests using coal-water slurry failed due to phase segregation of the coal particles in the liquid supply lines and within the atomizer. The triple-concentric atomizer chracterization was refined using the Malvern 2600. The tripleconcentric atomizer displays an eight-fold reduction in air mass flow requirements compared to a conventional coflow air assist atomizer. 


\section{Table of Contents}

Disclaimer 2

Abstract 3

Executive Summary $\quad 5$

Introduction $\quad 5$

Personnel Changes 5

$\begin{array}{ll}\text { Results and Discussion } & 6\end{array}$

$\begin{array}{ll}\text { Conclusion } & 6\end{array}$

$\begin{array}{ll}\text { Projected Activity for Next Period } & 7\end{array}$

\section{List of Figures}

Figure 1: SMD vs. Primary Air Pressure (Delavan Nozzle with Water) 8

Figure 2: Triple-Concentric Atomizer Schematic Cross-Section 8

Figure 3: SMD vs. Outer Air Flow Rate and Liquid Flow Rate 9

Figure 4: SMD vs. Center Air Flow Rate and Liquid Flow Rate 9

Figure 5: SMD vs. Air-to-Liquid Mass Ratio 10 


\title{
DESIGN OF ATOMIZERS AND BURNERS FOR COAL- WATER SLURRY COMBUSTION \\ Grant Number: DE-FG22-95PC95105 \\ Progress Report for Period 7/1/97 - 9/30/97
}

\author{
Wm. Humphrey and Dr. N. Chigier \\ Spray Systems Technology Center \\ Dept. of Mechanical Engineering, Carnegie Mellon University \\ Pittsburgh, PA 15213
}

\section{Executive Summary}

A Delavan internal-mixing air-assist atomizer was characterized with water prior to its use with coal-water slurries provided by Penn State University. The coal-water slurries could not be atomized due to particle sedimentation within the atomizer, leading to clogging of the nozzle.

The triple-concentric atomizer (TCA) was studied further using a Malvern laser diffraction particle sizer. The air mass flow rate required for atomization is reduced eight-fold compared to the same atomizer operated in a traditional air-assist mode.

Planned activities for the next quarter include investigation of the liquid sheet thickness and design of a series of TCAs with a variety of geometries for a parametric study of the operating conditions and performance.

\section{Introduction}

This report reviews the activities and results of the period 1 July 1997 to 30 September 1997 and the planned activities for the following period. The first section indicates personnel changes related to the project. The second section presents the activities and results from the current quarter. Lastly, highlights of the planned activities for the next quarter are given.

\section{Personnel Changes}

Dr. Adel Mansour, previously responsible for the research on this project, has left Carnegie Mellon University to pursue opportunities in industry after 8 years as a doctoral student, post-doctoral research fellow, and finally research faculty member. Rony Hitron, a post-doctoral research fellow, and William Humphrey, a doctoral student under Dr. Chigier, will be assuming this responsibility. 


\section{Results and Discussion}

The activities in this quarter focused on the attempt to measure droplet sizes in coalwater slurry sprays from the Delavan nozzle.

\section{Delavan Nozzle}

Initially, a Delavan nozzle was characterized using water. Measurements of aggregate drop size distributions were made with a Malvern 2600 laser diffraction particle sizer. The experiments varied the liquid and primary air flow rates across the available range. Liquid flow rate was controlled by pressurizing a reservoir with air. Figure 1 shows the results of Sauter mean diameter of water droplets versus primary air stagnation pressure at several liquid mass flow rates.

Next, samples of coal-water slurry were used. Six samples of various solid loading and stabilizer concentration were provided by the Pennsylvania State University. The slurry samples were placed on a shaker for 24 hours prior to each test to ensure that the solids were evenly distributed and well suspended. Due, possibly, to the high shear rates within the liquid feed lines, the coal particles precipitated out of the flow in the fittings connecting the reservoir to the nozzle. After replacement of all of the fittings and liquid supply lines with larger diameter components, the coal particles precipitated out of the slurry within the nozzle itself. No reasonable sprays were obtained with any of the six coal-water slurry samples provided by the Pennsylvania State University.

\section{Triple Concentric Atomizer}

The triple-concentric atomizer concept (see Fig. 2) was also further developed during this quarter. The drop size distribution characterization study with water was extended. Drop sizes were measured along the nozzle centerline at a point $20 \mathrm{~cm}$ downstream of the exit with the Malvern 2600. This drop size characterization was carried out to improve upon the previous work done with the Greenfield Digital Spray Analyzer. The Greenfield, to obtain an adequate data rate, required a combination of optical settings which prevented the instrument from detecting particles smaller than $20 \mu \mathrm{m}$. This limitation obviously leads to a significant bias in the reported size distribution.

Liquid flow rates varied from $3 \mathrm{~g} / \mathrm{s}$ to $6 \mathrm{~g} / \mathrm{s}$, outer air flow from $3 \mathrm{~g} / \mathrm{s}$ to $10 \mathrm{~g} / \mathrm{s}$, and center air flow from $0.3 \mathrm{~g} / \mathrm{s}$ to $1.8 \mathrm{~g} / \mathrm{s}$. Air velocities varied from $50 \mathrm{~m} / \mathrm{s}$ to $200 \mathrm{~m} / \mathrm{s}$ for the outer flow and $150 \mathrm{~m} / \mathrm{s}$ to $310 \mathrm{~m} / \mathrm{s}$ (sonic conditions) for the center flow. Figures 3, 4, and 5 illustrate the trends in average drop size with variation in the flow conditions. Note especially Figure 5 which highlights the increased efficiency of atomization with the central air stream compared with the outer air stream.

\section{Conclusion}

The TCA concept continues to be refined and extended. With the more accurate measurements offered by the Malvern 2600, the improvement in atomization of the center air 
stream over conventional twin-fluid atomizer arrangements can be accurately quantified. The increase in efficiency of the atomizer can be exploited in two ways: to reduce the energy consumption of the atomizer, or to increase the "power" of the atomizer for highly viscous liquids such as coal-water slurries, aqueous polymer solutions, paints, or heavy fuel oils.

\section{Projected Activity for Next Period}

The activity planned for the next quarter will focus on the triple-concentric atomizer.

- $\quad$ Laser Doppler velocimeter measurements will be made within the liquid sheet exiting the atomizer. This will allow determination of the thickness of the annular liquid sheet formed at the atomizer exit.

- An one-component Aerometrics Phase Doppler Particle Analyzer will be used to make more detailed spray measurements, including radial and axial variation in the droplet size distribution.

- $\quad$ Sprays of aqueous polymer solutions and heavy, high-viscosity liquids will be examined with the Greenfield Digital Spray Analyzer for visualization and the Malvern 2600 and the Phase Doppler Particle Analyzer for droplet size measurements.

- A theoretical analysis of the atomization mechanism(s) responsible for the reduction in average drop size when using the center air stream will begin.

- Design and construction of a series of new triple-concentric atomizers to explore the effect of atomizer geometry (especially the center air tube inset distance) will begin. 

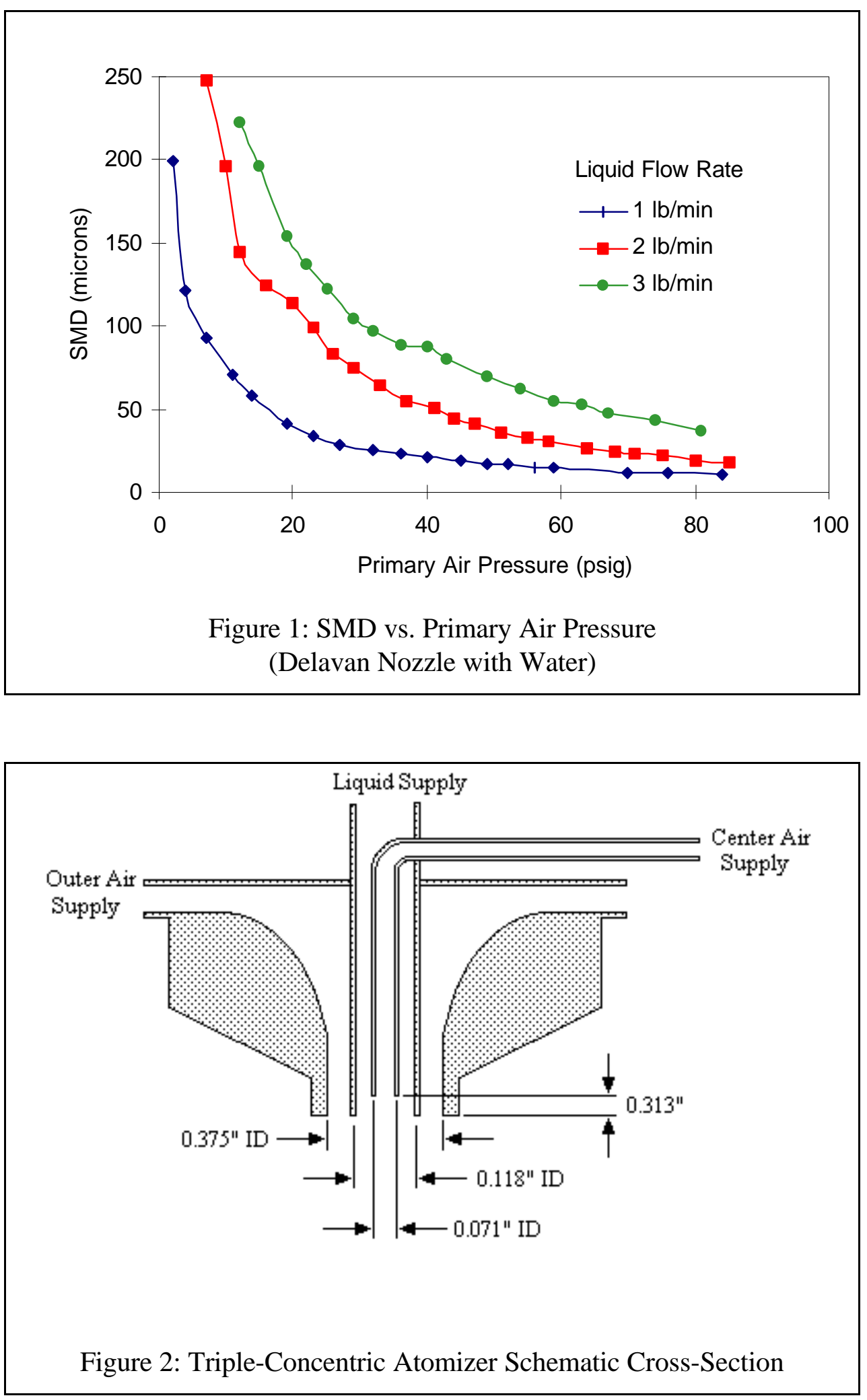


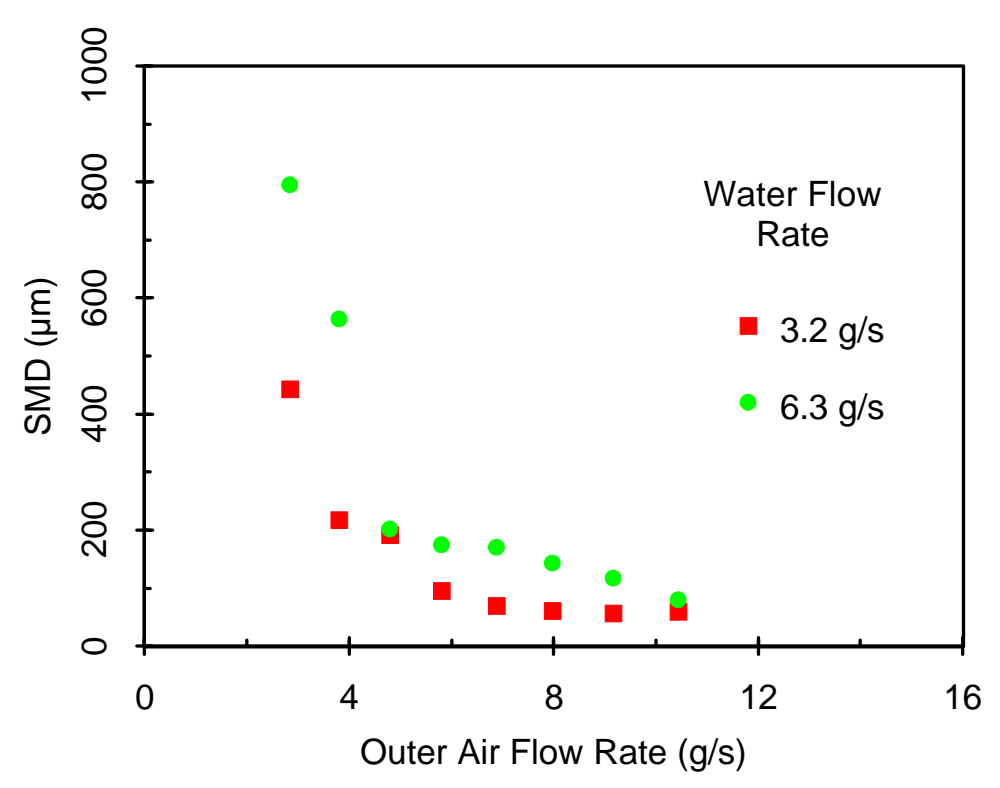

Figure 3: SMD vs. Outer Air Flow Rate and Liquid Flow Rate

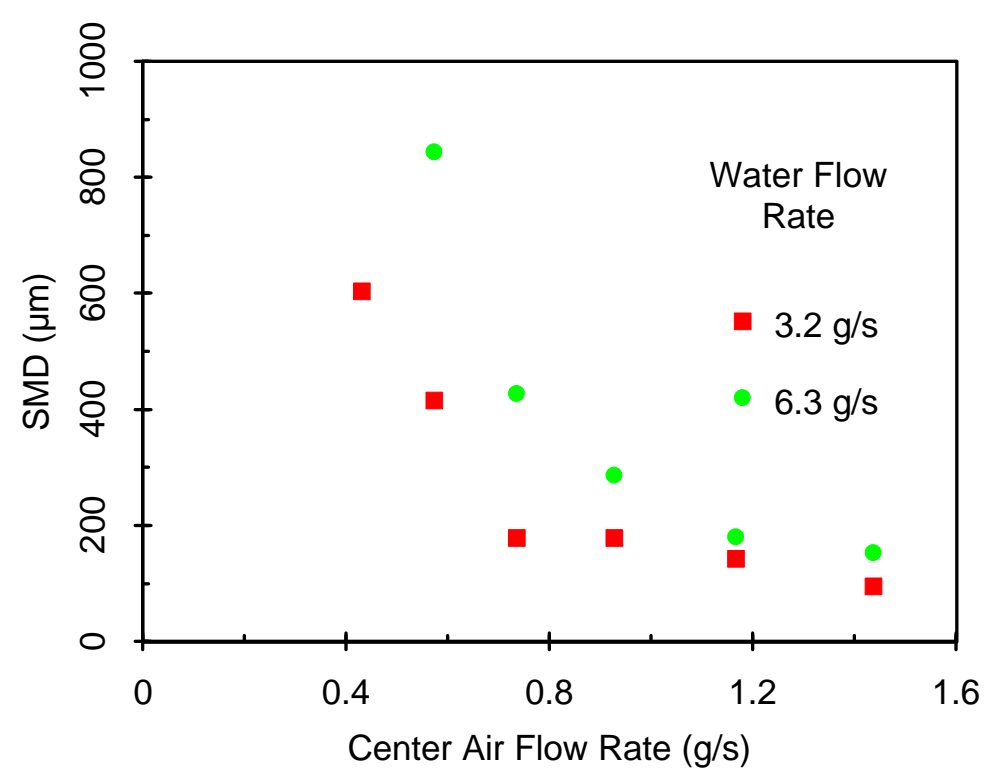

Figure 4: SMD vs. Center Air Flow Rate and Liquid Flow Rate 


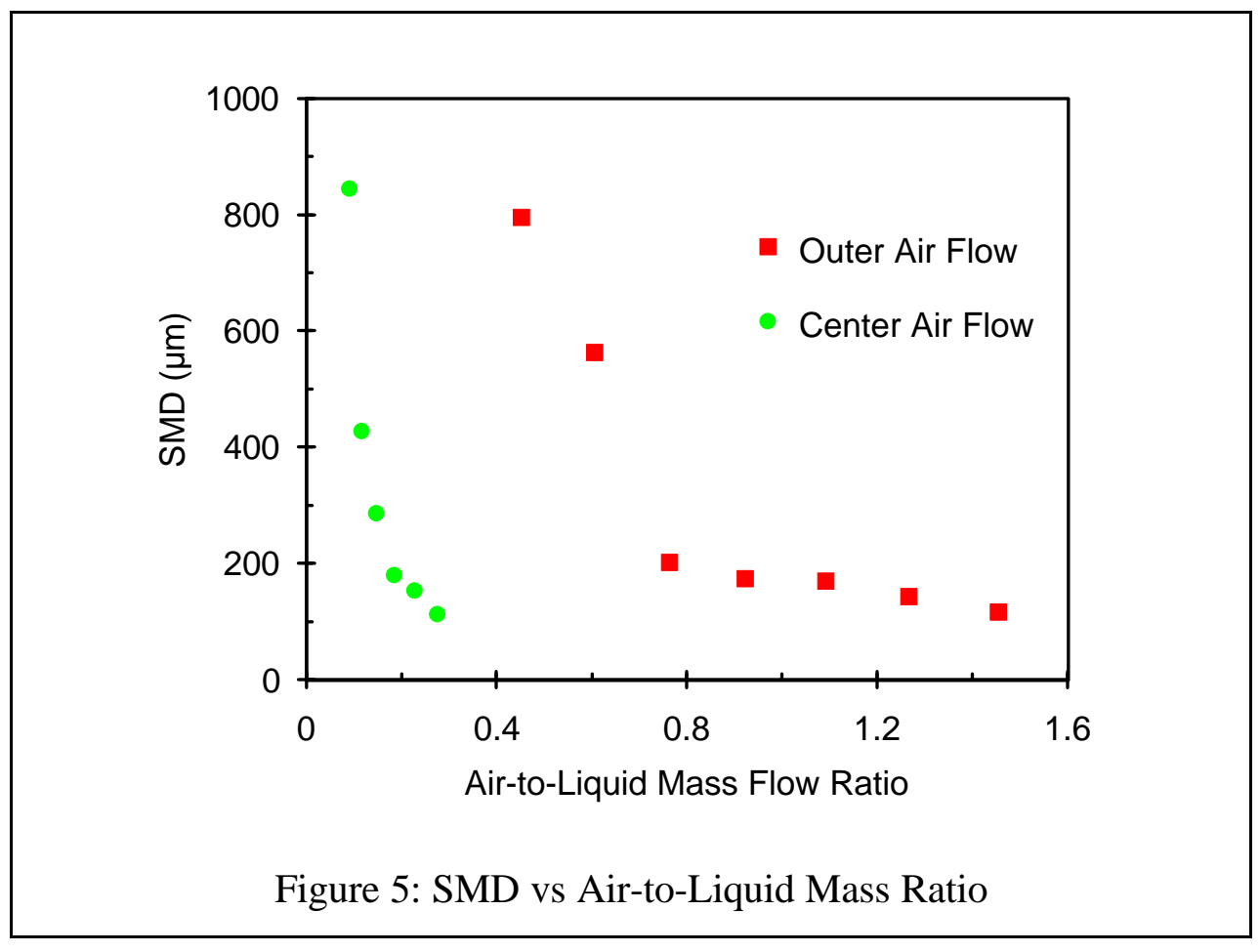

